\title{
Cryotherapy in Ophthalmology*
}

\author{
Shandiz Tehrani, Frederick W. Fraunfelder ${ }^{\#}$ \\ Casey Eye Institute, Oregon Health \& Science University, Portland, USA. \\ Email: "fraunfer@ohsu.edu
}

Received January $7^{\text {th }}, 2013$; revised February $8^{\text {th }}, 2013$; accepted March $5^{\text {th }}, 2013$

Copyright (C) 2013 Shandiz Tehrani, Frederick W. Fraunfelder. This is an open access article distributed under the Creative Commons Attribution License, which permits unrestricted use, distribution, and reproduction in any medium, provided the original work is properly cited.

\begin{abstract}
Cryogens have been used to freeze living tissue for the purpose of treating benign and malignant lesions. Within the last century, ophthalmologists have found cryotherapy to be useful in treating a variety of ocular pathologies. Here, we review the history of cryotherapy, its introduction to the field of ophthalmology, its proposed mechanism of action, and its current applications in treating surface and intraocular eye disease.
\end{abstract}

Keywords: Cryotherapy; Cryosurgery; Cryogenic Surgery; Cryoprobe; Cryospray; Liquid Nitrogen; Surface Eye Disease

\section{Introduction}

Cryotherapy (also known as cryocautery, cryogenic surgery, and cryosurgery) has been used to treat a variety of ophthalmic conditions, including surface and intraocular pathology. Cryotherapy may be preferable in treating certain surface and intraocular diseases (including benign and malignant lesions), as there are few post-operative adverse events and limited long-term complications when compared to radiation and chemotherapy. Here, we review the historical and current role of cryotherapy in ophthalmology.

\section{Historical Review}

The history of medical cryotherapy is a captivating one, and has been well documented by Lubritz [1], Cooper and Dawber [2], and Freiman and Bouganim [3], among others. The known benefits of cryotherapy date back to 2500 B.C., when ancient Egyptians used cold to soothe injuries $[1,4]$. Hippocrates used cold to relieve swelling, bleeding, and pain [5]. The first published report on freezing biologic tissue came from Arnott (1797-1883), who used freezing of tissue locally in the setting of tumors [6]. Using a salt and crushed ice mixture, Arnott used cryotherapy for palliation of pain in breast cancer,

\footnotetext{
*This report was supported by an unrestricted grant from Research to Prevent Blindness to Casey Eye Institute.

The authors have no relevant financial disclosures or interests.

\#Corresponding author.
}

uterine cancers, and treatment of some skin cancers. He also used his cold treatment for acne, neuralgia, and headaches, and was able to achieve temperatures of $-24^{\circ} \mathrm{C}$.

With the advent of liquefied gases, it was realized that a rapid freeze with a colder cryogen could effectively treat tumors. In 1899, White became the first to use commercially available refrigerants (liquefied gases) for medical care. He published reports on using liquid air for the treatment of lupus, herpes zoster, nevi, warts, chancroid, varicose leg ulcers, carbuncles, and epitheliomas [7,8]. Irvine and Turnacliffe expanded the uses of liquid air treatment to seborrheic keratosis, senile keratosis, lichen simplex, and poison ivy dermatitis [9].

Allington was the first to use liquid nitrogen in the treatment of skin lesions [10]. This became the preferred gas because liquid oxygen is explosive and the two gases have similar boiling points (oxygen $=-182.9^{\circ} \mathrm{C}$, nitrogen $=-195.6^{\circ} \mathrm{C}$ ). Allington used a cotton swab dipped in liquid nitrogen to treat skin tumors. Unfortunately, there was loss of the heat sink potential with the transfer between the cotton swab and the skin, rendering this method insufficient for effectively treating skin tumors and malignancies.

Cooper designed a liquid nitrogen probe that achieved a temperature of $-195.6^{\circ} \mathrm{C}$ [11]. He treated Parkinson's disease and inoperable brain tumors by freezing the thalamus and the lesion, respectively. Torre and Zacarian further advanced the field by developing hand held de- 
vices, which facilitated one-handed cryospray and cryoprobe procedures [12].

Liquid nitrogen cryotherapy spread to multiple specialties from that point forward [2]. Dermatologists advanced cryotherapy treatments of benign and malignant tumors of the skin. Neurosurgeons were able to perform liquid nitrogen-assisted transsphenoidal hypophysectomy. Liquid nitrogen treatment of oral and cervical cancers, as well as cryosurgery to the uterus, was described.

Today, liquid nitrogen is the most popular medical cryogen. Carbon dioxide (melting point $=-79^{\circ} \mathrm{C}$ ) is still used worldwide because of relatively easy storage. However, because of its higher boiling point, carbon dioxide is generally suitable for treating benign conditions only. Similarly, nitrous oxide (boiling point $=-89^{\circ} \mathrm{C}$ ) is favored by some gynecologists and oral surgeons, but only for benign lesions. Freon (boiling point $=-29.8^{\circ} \mathrm{C}$ to $-40.8^{\circ} \mathrm{C}$ ) has also been used to treat benign tumors. Currently, the acceptable minimal temperature to achieve cell death is $-50^{\circ} \mathrm{C}$ to $-55^{\circ} \mathrm{C}[13,14]$. The standard of care in dermatology, oral surgery, otolaryngology, neurosurgery, and gynecology is liquid nitrogen cryotherapy for malignancies $[2,15,16]$. Interestingly, this has yet to translate fully to ophthalmology, where multiple cryogens are used in lieu of liquid nitrogen for tumors in and around the eye.

\section{Early Advancements of Cryotherapy in Ophthalmology}

Cryotherapy of the eye was first reported by Bietti in 1933 [17]. He reported on the use of cryogenics to produce a thermal chorioretinitis to seal a retinal hole. The technique used a metal probe, pre-cooled in a mixture of carbon dioxide and acetone, with application of the probe to the outer wall of the eye overlying the retinal hole. Two years later, Deutschmann used cryosurgery in the form of solid carbon dioxide probes applied in the same fashion to treat retinal detachments [18]. It was not until 1961 that cryotherapy reemerged within the subspecialty of ophthalmology. Krwawicz developed a metal probe, which he immersed in a mixture of alcohol and solid carbon dioxide for the use of intracapsular cataract extraction [19]. Amoils improved cryoextraction techniques by developing a liquid nitrogen probe [20]. Over the next few years, cryoextraction of cataracts was adopted by many ophthalmologists around the world [21].

Advances in treatment of retinal detachments and retinal tears were also made with cryotherapy. Cryoretinopexy was done with various types of cryoapplicators. Bellows and Kelman created retinal cryopexy instruments for the treatment of retinal tears and for cryoextraction [22,23]. Schepens, Lincoff, and others were key figures in the advancement of cryoretinopexy surgical techniques and in using cryoretinopexy with scleral buckling for retinal detachments [24-26]. Application of a cryoprobe to the sclera for 5 seconds was shown to create a white area in the underlying retina and seal retinal tears and holes $[23,25]$. In most instances, solid carbon dioxide was utilized to achieve a temperature of $-50^{\circ} \mathrm{C}$ to $-60^{\circ} \mathrm{C}$.

After popularization of cryoretinopexy and cryoextraction, cryotherapy with different cryogens was used to treat a variety of benign and malignant eye diseases. In the 1950s and 1960s, advances in keratomileusis and lamellar corneal grafting techniques using a cryolathe and carbon dioxide snow, were put forth by Barraquer and Kaufman [27,28]. In 1972, Zacarian published the first series of cases using liquid nitrogen cryosurgery around the eye and orbit for tumors [29]. Fraunfelder and colleagues described cryosurgical treatment of ocular and periocular squamous cell carcinomas in cattle [30-32] and in humans $[33,34]$.

\section{Cryogens}

Ophthalmologists who do use cryotherapy primarily use freon (boiling point $=-29.8^{\circ} \mathrm{C}$ to $-40.8^{\circ} \mathrm{C}$ ), nitrous oxide (boiling point $=-88.5^{\circ} \mathrm{C}$ ), or solid carbon dioxide (melting point $=-79^{\circ} \mathrm{C}$ ) rather than liquid nitrogen (boiling point $=-195.6^{\circ} \mathrm{C}$ ) [16]. The boiling point of liquid nitrogen is by far the lowest of the available cryogens used in medicine, making it the most effective in cell destruction. It is well established in the dermatology literature that a rapid freeze of skin tumors with liquid nitrogen is much more effective than a slow freeze (using alternative cryogens) in eradicating tumor cells [35-40]. This is true in the eye as well, where a number of case series have shown the tumoricidal nature of liquid nitrogen [41-44].

The method of cryotherapy and types of cryogens used in the treatment of eye disease are not standardized within ophthalmology. In addition, the physiochemical and biological effects of the different cryogens on the ocular tissues have not been fully elucidated. Lastly, the lack of familiarity with the use and storage of liquid nitrogen further limits the exposure of ophthalmologistsin-training to this cryogen. Thus, the practice of ophthalmic cryotherapy is likely limited by the type of training the ophthalmologist received during the residency and fellowship years.

\section{Safety of Cryotherapy}

Although vertebrate cells and tissue are highly susceptible to the destructive effects of cryotherapy, not all pathogenic organisms are fully destroyed by exposure to liquid nitrogen or other cryogens. In fact, a slow freezing method followed by storage in liquid nitrogen allows for excellent cryopreservation of viruses, microorganisms, and cells. Using a cryoprobe (which is a closed system), 
involves no risk of contamination as there is no exposure of vapor or sprays arising from the cryogen. However, with an open system such as a liquid nitrogen cryospray, precautions must be taken to prevent contamination from the freezing agent. This is achieved by passing the liquid nitrogen through a cryogenic filter (including the Gelman and Millipore filters) when the liquid nitrogen tank is being filled. In addition, cold filters (including Brymill filters) may be used when transferring liquid nitrogen from the storage tank to handheld cryotherapy units. These filtration methods have consistently been shown to prevent transfer of bacteria, fungi, and molds [24,45,46].

Most complications from ocular cryotherapy with liquid nitrogen are related to surgeon inexperience and prolonged contact of a cryoprobe or cryospray with surface tissue. Many times, a novice cryosurgeon is unable to break the contact of the cryoprobe with the tissue, leading to an over-freeze. Depending on the tissue undergoing cryotherapy, the most common complications from cryotherapy include transitory uveitis, temporary chemosis, subconjunctival hemorrhage, corneal endothelial damage, paralysis of extraocular muscles from cryotherapy over muscle insertion sites, and sector iris atrophy [47]. Rarely, there have been reports of scleral melting after liquid nitrogen cryotherapy [48]. Although the abovementioned adverse events rarely have long-term consequences, cryosurgery with liquid nitrogen is not a benign procedure and requires practical experience. Novice cryosurgeons will need to observe and learn when and how to use cryotherapy to treat surface eye lesions and intraocular diseases prior to performing the procedure themselves.

\section{Cellular Effects of Cryotherapy}

The mechanism of cellular destruction during the freeze phase of cryotherapy is multifactorial and not yet fully elucidated. Some effects are well known, including ischemia through vascular stasis and the destruction of small caliber blood vessels, ice crystal formation inside cells leading to cell wall rupture, denaturing of lipidprotein complexes, osmotic stress, tissue necrosis, cellular apoptosis after freezing injury, and the buildup of toxic concentrations of solutes inside cells $[46,49,50]$. The latter mechanism is explained by cell dehydration, which occurs when water is withdrawn to make ice crystals intra- and extracellularly. As cryotherapy freezes extracellular fluid, pure water crystals form extracellularly, thus concentrating the remaining extracellular solutes. At the same time the extracellular water is forming ice, the intracellular water is cooling below its freezing point but not forming ice crystals. This is called supercooling. The cell membrane is permeable to supercooled water but not to ice crystals. The supercooled water will tend to flow out of the cell and freeze externally. The net result of this process is cellular dehydration and solute concentration intracellularly, which further destabilizes the cell [51].

The thaw phase of cryotherapy may be just as crucial as the freeze phase in cell destruction. A slow thaw allows for longer vascular stasis and longer exposure to toxic solute levels within the cell. The effect is enhanced by repeat freeze-thaw cycles, usually performed $2-3$ times. The depth of freeze is related to the contact time (the longer the application, the deeper the freeze) [46].

Which of the aforementioned mechanism leads to cell death during cryosurgery depends on the following factors: the cryogen employed (and thus the rate of freeze and the final temperature achieved), the method and length of application, the number of freeze-thaw cycles, the type of cells being frozen, the water content and vascularity of the tissue, and the rate of thaw. In regards to the type of cells undergoing cryotherapy, it has been shown that melanocytes are very sensitive to freezing. Hence there is a risk of depigmentation of skin after cutaneous cryosurgery [46]. Collagen is the most resilient tissue, and cartilage necrosis is extremely rare with cryotherapy. Thus, cryosurgery is particularly suitable in areas where maintenance of elasticity and structure are important.

The ability of a cryogen to freeze depends not only on its boiling point, but also upon the method by which it is applied to biologic tissue. If a thermocouple is placed within a living tissue at a location next to the application of a cryoprobe, a rapid and precipitous temperature fall will be appreciated in the beginning. This will be followed by a slow fall in the temperature until a point is reached where the temperature equilibrates despite continuous cryogen application. This is because the cryogen acts as a heat sink while the surrounding tissues, reheated by blood vessels, resupply heat. The heat sink essentially loses efficiency with distance so that it is less effective in removing heat from the tissues at increasing distances from the cryoprobe application point. Eventually a point is reached when heat is being renewed as fast as it is being extracted, a steady state condition occurs and the final temperature remains constant [52]. We have simulated the above scenario in the lab using non-living animal tissue, a liquid nitrogen cryospray, and a thermocouple (Figure 1).

Research by Wilkes and Fraunfelder nicely illustrated the salient factors in cellular and clinical ophthalmic cryosurgery [46]. The ability of a cryogen to freeze is dependent on its ability to remove heat, which is determined by its boiling point. The ice ball produced by a cryoprobe becomes warmer as distance from the cryoprobe is increased. The broad categories of in vivo cryoinjury include intracellular and extracellular ice formation and ischemic infarction. A rapid freeze and a slow 


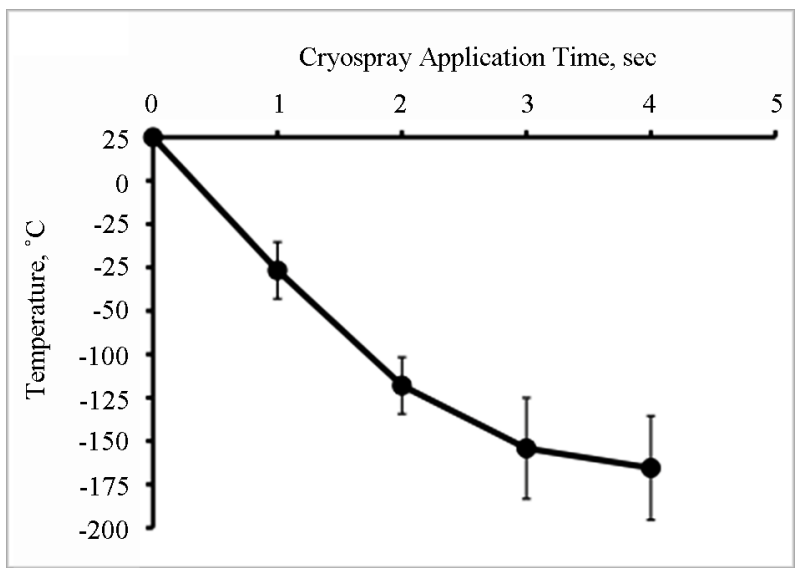

Figure 1. Tissue temperature with liquid nitrogen cryospray application. Using a Brymill liquid nitrogen cryospray, non-viable chicken skin at room temperature, and a $24 \mathrm{~g}$ thermocouple (inserted superficially), liquid nitrogen was sprayed at a distance of $<1 \mathrm{~cm}$. Five readings at each time point were recorded. Error bars represent standard deviations.

thaw produce the most cell death. Multiple freeze/thaw cycles are more destructive for both normal and pathologic tissue than a single cycle. The pathologic hallmark of cryotherapy is ischemic necrosis. Large blood vessels are highly resistant to cryoinjury, while microvasculature is susceptible. Peripheral nerves are sensitive to cryoinjury. Melanocytes are sensitive to cryoinjury, while the destruction of hair follicles occurs with double freeze/ thaw cycles to $-20^{\circ} \mathrm{C}$. Infection is rare after cryosurgery. Edema occurs after cryosurgery and resolves over 1 - 2 weeks. Healing time after cryosurgery ranges from $3-6$ weeks.

\section{Cryotherapy for Surface Eye Pathology}

\subsection{Special Considerations}

When freezing skin tumors or eyelid tumors, the temperature of the underlying tissue can be monitored by inserting a thermocouple. For cryosurgery on the surface of the eye, this is not practical. One cannot insert a thermocouple into the sclera or cornea of the eye without putting the patient at risk of long-term scarring, infection, or globe perforation. To overcome this obstacle, a series of experiments were undertaken by Fraunfelder and Wingfield [43]. These findings described a microspatula thermocouple which was placed, through a vertical incision, into the cornea of human eye bank eyes or anesthetized dog eyes. A cryoprobe was then applied adjacent to the thermocouple. If the cryoprobe was placed on the surface of the globe for only 2 - 3 seconds, no drop in temperature was recorded on the microthermocouple, suggesting that this was a safe amount of time to apply a cold liquid nitrogen cryoprobe. In contrast, prior research by Fraunfelder and associates revealed loss of endothelial cells with freezing times approaching 5 seconds. A temperature of $-25^{\circ} \mathrm{C}$ at the level of the endothelium will kill these fragile cells, and an ice ball of $5 \mathrm{~mm}$ or larger did lead to endothelial cell loss. Based on the data from these studies, a series of surface eye malignancies were treated with liquid nitrogen cryotherapy, taking care to keep the contact time of the cryoprobe to less than 3 seconds, and usually 1 - 2 seconds.

\subsection{Benign Pathology}

\subsubsection{Advancing Wavelike Epitheliopathy}

The etiology of advancing wavelike epitheliopathy (AWLE) is probably multifactorial. It has been hypothesized that prior ocular surgery, contact lens wear, contact lens solution, glaucoma drop toxicity, and underlying inflammatory or dermatologic disorders may all cause this condition [53]. Confocal microscopy has shown the presence of atypical elongated cells oriented centripetally with hyperreflective nuclei. Pathologic diagnosis is consistent with unremarkable corneal epithelium when stained with hematoxylin-eosin, with no evidence of cytologic alterations or dysplastic change, while full-thickness conjunctival biopsies have revealed parakeratosis of the conjunctival epithelium with underlying focal mononuclear cell infiltrates compressing and extending into the overlying epithelium [53]. Patients with AWLE present with foreign body sensation or blurred vision. AWLE is diagnosed by a well-demarcated patch of coarse, irregular epithelium which appeared in recurrent waves extending from the limbus towards the visual axis. The waves were most easily seen by shining a broad slit-lamp beam tangentially across the surface of the cornea, or with sclerotic scatter revealing the distinct margins. One of the only published treatment method to date describes the application of $1 \%$ silver nitrate solution to the corneoscleral limbus with removal of the corneal epithelium through debridement [53].

Liquid nitrogen cryotherapy for AWLE was described in a 2006 series [54]. Using a cryospray, a double freezethaw was performed on the corneoscleral limbus and surface corneal epithelium of 5 eyes affected by AWLE. With a median follow-up of 15 months, AWLE resolved within 2 weeks without recurrence or the need for repeated cryotherapy. Four of the five eyes had a history of glaucoma on topical medication and 2 had a history of corneal transplantation. None of the patients in this series wore contact lenses. Visual acuity improved only slightly in all subjects and antecedent eye disease, such as cataracts, glaucoma, and irregular astigmatism, limited the best-corrected visual acuity. There were no surgical complications as a result of treatment with liquid nitrogen cryotherapy spray. 
As the liquid nitrogen spray creates a superficial freeze when applied for less than 1 second, the unwanted corneal epithelium can be frozen without damage to the underlying corneal stroma or endothelium. In addition, localized cryotherapy spares the non-treated corneal surface and limbus, preserving the regenerative potential of the corneal epithelium. Liquid nitrogen cryotherapy, using the spray technique described, appears to be an effective means of eradicating AWLE and may be used as an alternative to silver nitrate $1 \%$ solution.

\subsubsection{Conjunctival Amyloidosis}

Conjunctival amyloidosis is rarely associated with systemic disease $[55,56]$. The etiology of primary ocular conjunctival amyloidosis has not been fully elucidated. However, it likely involves production of precursor immunoglobulin light-chains by a population of benign, localized B-lymphocytes, followed by deposition of amyloid in the conjunctiva [57]. Patients may present with painless swellings of the conjunctiva or eyelids, pseudoptosis, or epiphora [58]. Clinically, the conjunctival lesions appear as small, pink-red or yellow-red nodules which are well-vascularized, and involving the palpebral and forniceal conjunctiva [58]. Histologically, conjunctival amyloidosis appears as an acellular, amorphous, eosinophilic material with the characteristic staining with Congo-red of dichroic birefringence. The traditional treatment of localized conjunctival amyloidosis has been surgical debulking, with repeat debulking surgery should the amyloidosis recur [55,57].

Liquid nitrogen cryotherapy of primary ocular conjunctival amyloidosis was recently reported in a series of 4 patients [59]. Liquid nitrogen cryospray was applied to the lesions, either directly or after excisional biopsy to debulk the amyloid lesions. With a median follow-up of 24.5 months, 2 of the 4 patients had post-treatment recurrence of conjunctival amyloidosis after the first treatment, at 14 and 10 months respectively. Conjunctival amyloidosis was eradicated in all subjects after repeat cryotherapy. Surgical debulking prior to cryotherapy may be beneficial in allowing the freezing to reach the deeper blood supply of the lesions.

\subsubsection{Conjunctival Lymphangiectasia}

Conjunctival lymphangiectasia is characterized by dilated and prominent lymphatic channels within the conjunctiva. The condition is usually unilateral, however bilateral cases may be seen in Turner syndrome or NonneMilroy-Miege disease. Symptoms include ocular irritation, dryness, epiphora, blurred vision, and pain [60]. The terms lymphangiectasia and lymphangioma are used interchangeably, and if there is bleeding into the lymph channels, the condition is called hemorrhagic lymphangiectasia [61]. The etiology of lymphangiectasia remains unknown. Simple excision or marsupialization, or both, have been the traditional therapeutic options for this condition.

The use of cryosurgery to treat hemorrhagic lymphangiectasia was first reported in 1975 [62]. A case series of conjunctival lymphangiectasia treated with liquid nitrogen cryotherapy was reported in 2009 [63]. Using a cryoprobe, cryotherapy was applied in a double freeze-thaw fashion after an incisional biopsy of a portion of the conjunctiva in 4 patients with conjunctival lymphangiectasia. With a mean follow-up of 24.5 months, 2 patients remained lesion free after therapy, while the other 2 patients had recurrence. The average time to recurrence was 18 months after therapy. Repeat cryotherapy led to resolution of recurrent conjunctival lymphangiectasia in all patients treated.

\subsubsection{Conjunctival Sarcoidosis}

Sarcoidosis is a chronic, multisystem, granulomatous disorder of uncertain etiology. Organ systems involved include the lungs, skin, lymph nodes, and eyes. Ocular symptoms are present in a significant portion of patients with systemic sarcoidosis, with the most common of these symptoms being uveitis and conjunctival nodules [64]. Biopsy of conjunctival nodules is sometimes performed to aid in the diagnosis of sarcoidosis. These nodules are typified by the presence of non-infectious, noncaseating granulomas. The nodules can create ocular irritation and foreign body sensation. Treatment of these nodules include lubrication, topical cyclosporine [65], or excision. Liquid nitrogen cryotherapy has recently been shown to treat conjunctival sarcoidosis in a 54-year-old woman [66]. In this case, multiple, bilateral, bi-psyproven conjunctival sarcoid nodules were treated with liquid nitrogen cryospray. The patient remained free of conjunctival sarcoidosis 6 months after cryotherapy.

\subsubsection{Conjunctival Vascular Tumors}

Vascular tumors of the conjunctiva include capillary hemangiomas, varices, and hemangiopericytomas. Depending on the type, management of these tumors typically includes local excision, $\mathrm{CO}_{2}$ laser, cautery, topical corticosteroids, or oral propanolol. Given their inherent vascular nature, these tumors may be especially susceptible to cryotherapy if easily accessible. A case report of a liquid cryotherapy to treat a conjunctival vascular tumor was reported in 2005 [44]. This report was a case of presumptive acquired conjunctival capillary hemangioma as the patient declined an excisional biopsy. Using a cryospray method, the lesion underwent liquid nitrogen cryotherapy, with significant regression of the lesion over 6 weeks. The lesion remained at its minimal size 1 year after therapy, although it had not completely regressed. It remains to be seen if certain vascular tumors would 
benefit from adjuvant cryotherapy if traditional therapies prove to be ineffective.

\subsubsection{Pterygia}

Pterygia are benign, wing-shaped folds of conjunctival and fibrovascular tissue extending over the limbus and encroaching onto the superficial cornea. Proliferation is thought to arise from activated limbal epithelial stem cells. The etiology of pterygia is unknown, but epidemiologic studies have implicated ultraviolet light, exposure to the environment, and chronic irritation as causative factors [67-69] These external factors may disrupt the apoptotic and anti-proliferative signals of epithelial stem cells $[70,71]$. The current definitive therapy for pterygia is surgical removal. Without additional treatment of the surgical bed after excision, pterygia excision is often complicated by recurrence. Various post-excision, adjuvant treatments have been described in the past, with recurrence rates of $6 \%$ with conjunctival autograft, $13 \%$ with beta-irradiation, and $29 \%$ with mitomycin C compared to $53 \%$ with excision alone after more than 5 years of follow-up [72].

The use of adjuvant liquid nitrogen cryotherapy of the surgical site after de novo and recurrent pterygia excision was recently described [73]. In this series, after excision of the pterygia, cryotherapy with a cryoprobe was performed, with the tip of the cryoprobe in contact with the corneoscleral limbus for approximately 1 second. A double freeze-thaw technique was used. In the de novo pterygia group (median follow up of 24.5 months), only 1 out of 15 patients had a recurrent pterygium after excision and cryotherapy, resulting in a recurrence rate of $3.3 \%$ per year. In the recurrent pterygia group (median follow up of 27 months), 4 out of 6 patients had a recurrent pterygium after excision and cryotherapy, resulting in a recurrence rate of $29.6 \%$ per year. Thus, liquid nitrogen cryotherapy appears to be an appropriate adjuvant treatment after de novo pterygia excision to minimize recurrence (Figure 2(a) and (b)). However, recurrent pterygia have not been shown to be susceptible to adjuvant liquid nitrogen cryotherapy, with high rates of recurrence despite cryotherapy [73].

\subsubsection{Superior Limbic Keratoconjunctivitis}

The etiology of superior limbic keratoconjunctivitis (SLK) remains uncertain. One proposed mechanism is soft tissue microtrauma between the superior palpebral and superior bulbar conjunctival surfaces from normal repetitive eye blinking in susceptible individuals [74-76]. Another hypothesis indicated an insufficient local tear supply [77-79]. A multitude of treatments are suggested for SLK, including thermocautery, chemocautery, conjunctival resection, punctual occlusion, topical application of autologous serum, topical cyclosporine, topical ketotifen

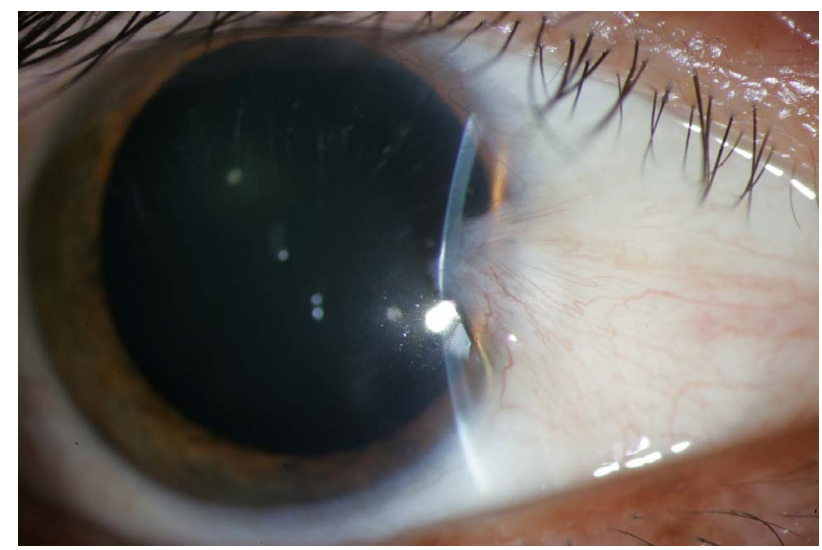

(a)

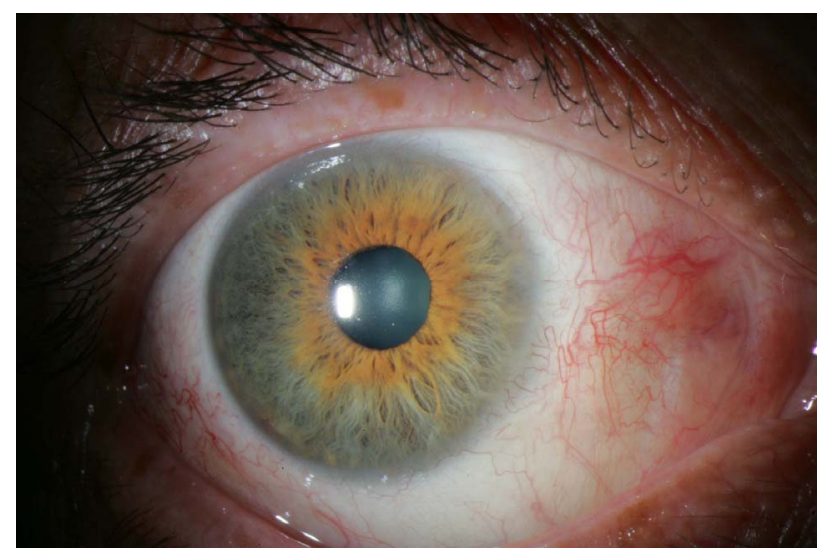

(b)

Figure 2. (a) Pterygium before excision and cryotherapy; (b) Appearance of eye 1 year after excision and cryotherapy.

fumarate, bandage contact lenses, topical lodoxamide tromethamine, botulinum toxin, and topical vitamin A eyedrops [77-84]. The fact that there are so many treatments frequently means that no single treatment is adequate, and that the disease may be a result of a combination of factors including dry eyes, mechanical trauma, local inflammation, and the effect of Graves disease on the eyes [85].

SLK typically presents with one or more of the following clinical symptoms: unilateral or bilateral ocular burning, foreign body sensation, ocular pain, epiphora, photophobia, blepharospasm, and decreased vision. Some patients have mucus discharge and corneal filaments. Examination findings include superior conjunctival inflammation with fine punctate staining by rose bengal of the upper cornea, superior limbus, and adjacent conjunctiva. Filaments are sometimes present at the superior limbus, with some patients exhibiting pseudoptosis. There is usually a fine papillary reaction of the upper eyelid palpebral conjunctiva.

A case report of liquid nitrogen cryotherapy for the treatment of SLK refractive to medical therapy was reported in 2009 [86]. Four patients underwent liquid ni- 
trogen cryospray with a double freeze-thaw technique to the superior limbus and inflamed conjunctiva (Figure 3(a) and (b)). Resolution of symptoms and signs occurred within 2 weeks in all cases. The SLK recurred in 2 of 4 patients with a median follow-up of 10 months. Recurrences were treated with another round of liquid nitrogen cryotherapy (mean time to recurrence 3.6 months), while no eyes required a third treatment. Liquid nitrogen cryotherapy of SLK may act by removing the redundant superior conjunctiva by causing a scar to form between the superior bulbar conjunctiva and the underlying Tenon's capsule and sclera [86]. It remains to be seen if the effects of cryotherapy on SLK are permanent.

\subsubsection{Trichiasis}

Trichiasis is a misdirection of eyelashes that is acquired. In-turning if eyelashes and their subsequent contact with the cornea and conjunctiva leads to foreign body sensation by the patient. Treatment modalities for trichiasis include manual epilation, electrolysis, cryotherapy, argon

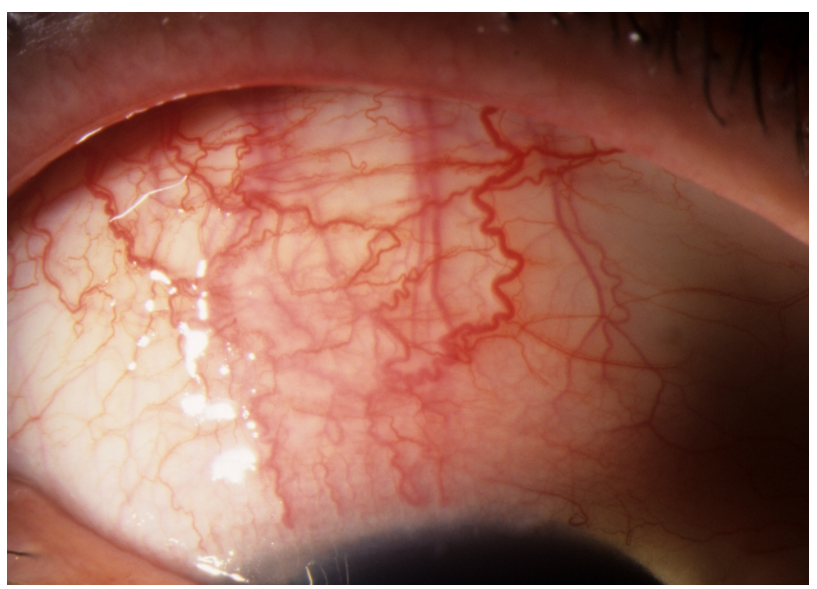

(a)

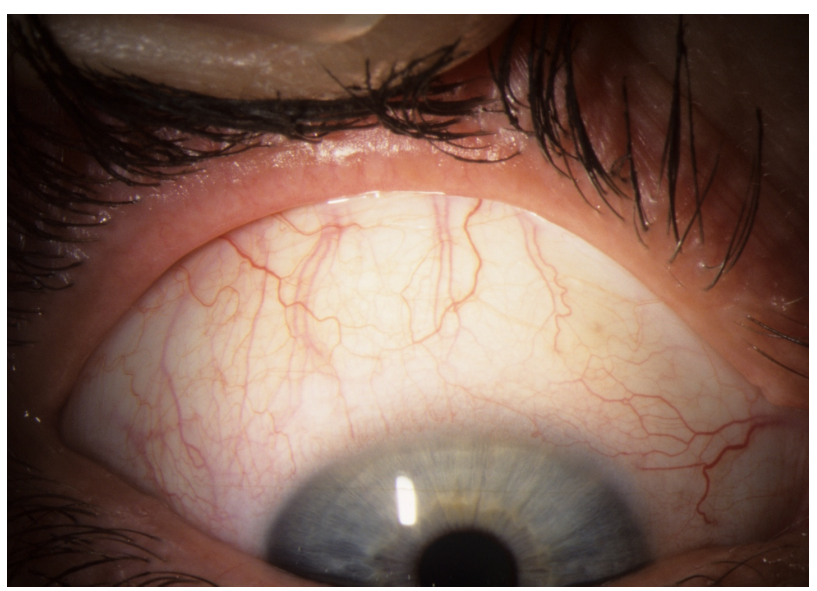

(b)

Figure 3. (a) Superior limbic keratoconjunctivitis (SLK); (b) Appearance of superior limbus 6 months after cryotherapy for SLK. laser, radiofrequency epilation and surgery.

Cryotherapy for trichiasis was first reported in 1997, using a nitrous oxide cryoprobe [87]. In this series, local treatment of eyelids using a double freeze-thaw technique and a microthermocouple achieved a low temperature of $20^{\circ} \mathrm{C}$ [87]. The use of liquid nitrogen for trichiasis cryotherapy was reported soon after, with success in greater than $90 \%$ of patients [88]. Subsequent use of cryotherapy to treat trichiasis in the setting of trachoma [89] and ocular cicatricial pemphigoid [90] has been reported. While highly successful, cryotherapy is not recommended for trichiasis in the setting of paralytic lids, heavily pigmented patients, or trichiasis involving less than one-third of the eyelid margin [88].

\subsubsection{Vernal Keratoconjunctivitis}

Vernal keratoconjunctivitis (VKC) is an immune-mediated disorder affecting the ocular surface, with a combination of environmental triggers and a pro-inflammatory state contributing to the pathogenesis. Clinical findings include the presence of upper tarsal giant papillae, corneal shield ulcers, or gelatinous limbal infiltrates (HornerTrantas dots). The giant papillary changes in VKC are collections of neutrophils, eosinophils, lymphocytes, and other leukocytes surrounding a central vascular core [91]. Patients with VKC usually present with symptoms of ocular itching, tearing, mucus secretion, and photophobia.

Cryotherapy for VKC has been reported by several groups, with the first report appearing in 1982 [92]. Singh reported a $22 \%$ recurrence rate with short-term follow up using a carbon dioxide cryogen [92]. Abiose and Merz, also using a carbon dioxide cryogen, had a $50 \%$ recurrence of giant papillae at just 4 weeks post treatment [93]. Mtanda and Sangawe studied 34 eyes with VKC treated with a carbon dioxide cryogen with disease recurrence in 2 eyes at 5 months [94]. Sankarkumar et al. studied 30 eyes of 15 patients with VKC, who underwent treatment a carbon dioxide cryogen. Reported recurrence was only $3.3 \%$ at one year [95]. Jiang et al. combined resection, cryotherapy, and amniotic membrane transplantation for the treatment of VKC [96]. In this study of 16 eyes (follow-up ranging between $3-22$ months), fourteen eyes $(87.5 \%)$ were symptom-free 1 month after surgery with no evidence of VKC on exam. Recurrence of VKC was observed in 2 eyes (12.5\%) after cryotherapy.

Liquid nitrogen cryotherapy (using a cryoprobe) for $\mathrm{VKC}$ in 3 eyes was reported in 2008 [58]. The median follow-up was 24 months. Although clinical symptoms and visual acuity improved 1 month after therapy, giant papillae recurrence was noted after 1 month. Recurrent VKC was noted as early as 9 months after therapy. The median time to recurrence was 12 months. 
Although cryotherapy may kill the central vascular core of giant papillae early on (resulting in some positive results after therapy), the high rate of recurrence may make cryosurgery an ineffective therapy for VKC. In addition, given the environmental and systemic factors that contribute to VKC, recurrence is likely in the absence of continued anti-inflammatory and immunosuppressive therapy.

\subsection{Pre-Malignancy and Malignancy}

\subsubsection{Primary Acquired Melanosis and Melanoma of the Conjunctiva}

Primary acquired melanosis (PAM) of the conjunctiva is a pre-malignant transformation of melanocytic cells. PAM occurs in up to $35 \%$ of adult Caucasians [97], while cases have been reported in highly pigmented individuals [98]. The presentation of PAM is usually unilateral, although bilateral cases have been reported [98]. The majority of PAM conjunctival lesions is painless and asymptomatic, and may involve the cornea. However, a small portion of PAM lesions may give rise to conjunctival melanoma. In a large series of over 300 eyes with PAM, it was estimated that $8 \%$ of PAM cases evolved into melanoma at 5 years, $12 \%$ at 10 years, and $21 \%$ at 15 years [98].

The mainstay of PAM management includes observation for malignant behavior (i.e. enlargement). Lesions with high suspicion for malignant transformation may be treated surgically, including excisional biopsy followed by intra-operative double freeze-thaw cryotherapy. Cryotherapy for the treatment of PAM was first described in the early 1980's [99]. Excision and cryotherapy of PAM has proven to be an effective treatment [100], although recurrences are not unusual. In a recent report of over 100 cases of PAM treated with excision and cryotherapy, and at least 3 years follow-up, the reported rate of PAM recurrence was $27 \%$, with $3 \%$ progressing to melanoma [98].

Conjunctival melanoma can arise de novo, from a preexisting nevus, or from PAM. By far, PAM is the most common precursor to conjunctival melanoma, with up to $75 \%$ of conjunctival melanomas arising in association with PAM [101]. As in PAM, conjunctival melanoma is often seen in lightly pigmented individuals. Conjunctival melanomas typically present as pigmented, fleshy, raised lesions, and may exhibit a prominent feeder vessel (Figure 4(a)). Malignant conjunctival melanoma metastasize to regional lymph nodes and other organs, including brain.

Treatment of conjunctival melanoma varies according to the extent and location of involvement [100]. Adjuvant cryotherapy for conjunctival melanoma was described as early as 1980 [102,103]. Melanomas involving the bulbar conjunctiva and cornea may be treated by alcohol epithe- liectomy and partial scelroconjunctivectomy using the "no-touch" technique, followed by intra-operative double freeze-thaw cryotherapy (Figure 4(b) and (c)). In addition to the above, melanomas involving the forniceal conjunctiva may require larger excision and mucous/ amniotic membrane grafts. Conjunctival melanotic le-

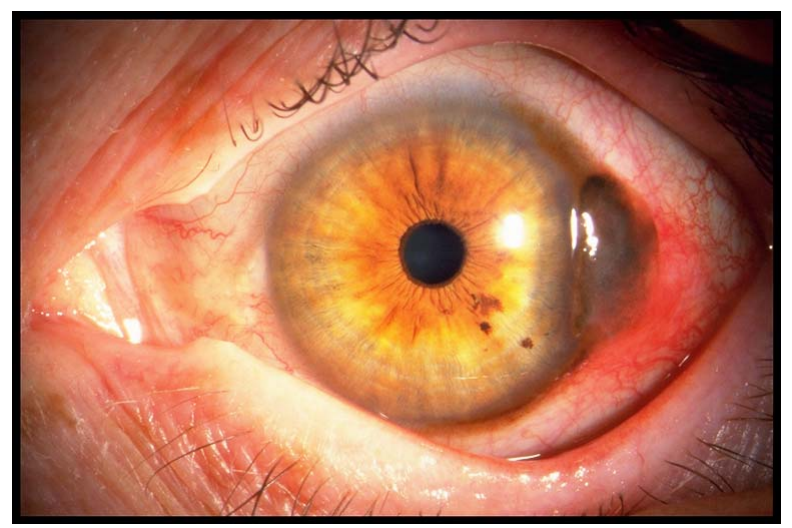

(a)

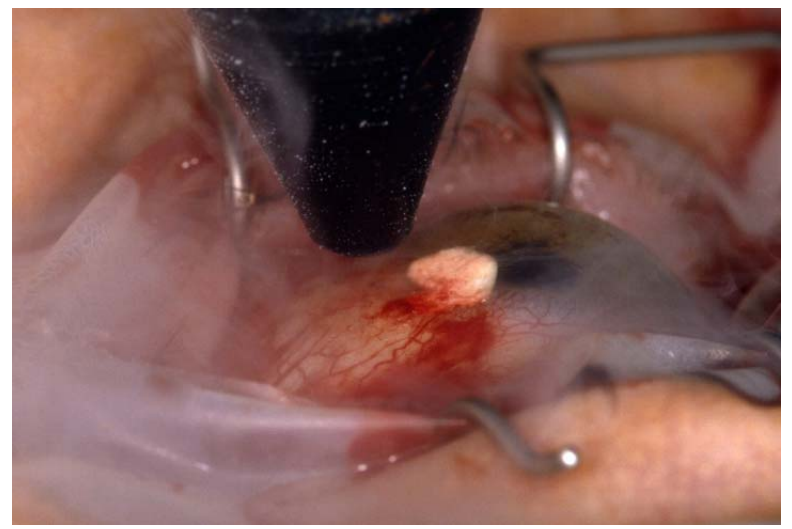

(b)

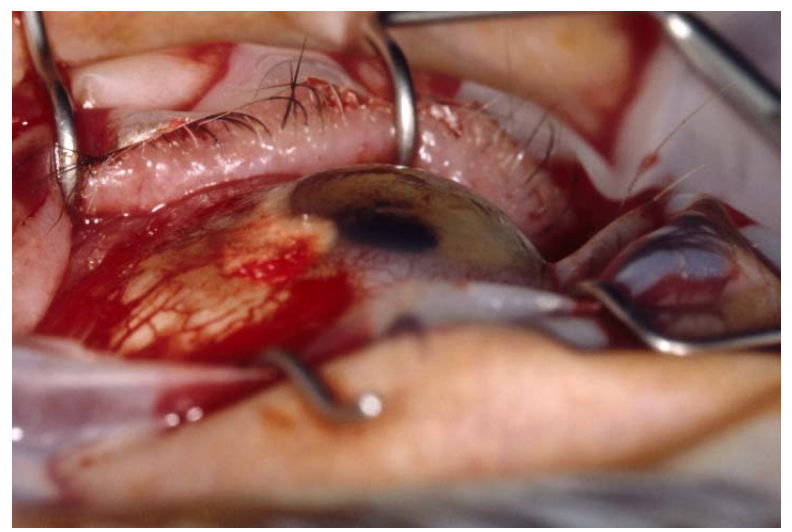

(c)

Figure 4. (a) Paralimbalconjunctival melanoma; (b) Paralimbal bed after removal of a conjunctival melanoma. Note the liquid nitrogen cryoprobe prior to application to the paralimbal region; (c) Paralimbal bed in (c) immediately after application of the liquid nitrogen cryoprobe. Note the frozen ice ball on the surface on the eye. 
sions that extent into and beyond the globe may require enucleation and exenteration. Metastatic melanomas require systemic therapy.

\subsubsection{Conjunctival Intraepithelial Neoplasia and Squamous Cell Carcinoma}

Conjunctival intraepithelial neoplasia (CIN) is a localized squamous cell neoplasm that is minimally aggressive and confined to the surface epithelium. Classification and grading of CIN is based on the depth of involvement of dysplastic cells: mild CIN involves $\sim 1 / 3$ of the epithelial depth, moderate CIN involves $\sim 1 / 2$ of the epithelial depth, and severe CIN (previously called carcinoma in situ) involves full thickness epithelium without invasion beyond the epithelial basement membrane. If the basement membrane is compromised and invaded by the abnormal cells, then the lesion has progressed to squamous cell carcinoma.

Conjunctival intraepithelial neoplasia and squamous cell carcinoma occur more frequently in immunocompromised individuals (including individuals with acquired immunodeficiency syndrome). Other possible risk factors include sun exposure and human papillomavirus infection [104]. Clinically, CIN and squamous cell carcinoma may present as fleshy, elevated lesion at the limbus. Adjacent corneal epithelial involvement is not uncommon. Although squamous cell carcinoma is locally invasive, it rarely metastasizes.

Adjuvant cryotherapy for CIN and squamous cell carcinoma was first proposed in 1977 [34]. Early studies using excision followed by nitrous oxide cryoprobes showed relatively good results with a $9 \%$ recurrence rate with at least 5 years of follow up [105]. More recently, an optimized technique for excision and cryotherapy has been described (similar to conjunctival PAM and melanoma excision and cryotherapy), which includes treatment of the lesion by alcohol epitheliectomy and partial scelroconjunctivectomy using the "no-touch" technique, followed by intra-operative double freeze-thaw cryotherapy [100]. In a study of 60 patients with CIN and conjunctival squamous cell carcinoma treated with excision and cryotherapy, after a mean follow up of 56 months, the rate of recurrence was $4.5 \%$ for CIN and $5.3 \%$ for squamous cell carcinoma [106].

\subsubsection{Reactive Lymphoid Hyperplasia and Conjunctival Lymphoma}

Reactive lymphoid hyperplasia (RLH) is a benign proliferation of lymphoid tissue in the ocular adnexa, which may present unilaterally or bilaterally. Histologically, RLH lesions appear as polymorphic proliferations of small lymphocytes and intermixed plasma cells, immunoblasts, and histiocytes. Conjunctival RLH is usually asymptomatic, with patients seeking medical attention because of cosmetic appearance or the fear of an uncertain diagnosis. The forniceal, bulbar, and palpebral conjunctivae can be affected, with a predilection for the fornices. RLH lesions have a potential for malignant transformation and systemic lymphoma, necessitating an excisional biopsy to rule out malignancy. Traditionally, conjunctival RLH has been treated with excision, while adjuvant radiation was reserved for biopsy-proven malignant lesions.

Cryotherapy for reactive lymphoid hyperplasia of the conjunctiva was first described in 1977 [33,34]. Eichler and Fraunfelder reported a retrospective case series of various conjunctival lymphoid tumors (including RLH) treated by liquid nitrogen cryospray [41]. With a mean follow up of 75 months, 5 biopsy-proven lymphoid hyperplastic lesions were treated. Four out of five lesions were locally eradicated after only 1 treatment, while the fifth lesion was eradicated after repeat treatment. Thus, it appears that cryotherapy is a viable option in treating RLH.

Conjunctival lymphoma is on the same spectrum as $\mathrm{RLH}$, with the former being malignant. The great majority of conjunctival lymphomas are B-cell in origin, with $\mathrm{T}$-cell lymphomas presenting in extremely rare cases [107]. Most conjunctival lymphomas are localized and not associated with systemic disease at presentation. However, systemic involvement may occur over time. Clinically, conjunctival lymphomas present in a similar fashion to RLH and may appear as a salmon pink, smooth, and soft lesion. Histopathologically, while RLH demonstrates a polycolonal expansion of lymphoid cells, malignant lymphoma is characterized by a diffuse sheet of monotonous, small, round lymphocytes, and may exhibit nuclear and mitotic features suggestive of higher malignant potential.

Diagnosis and treatment of localized conjunctival lymphoma includes excisional biopsy and adjuvant therapy, which has included external beam radiation, brachytherapy, cryotherapy, intralesional interferon injections, and systemic rituximab [108]. Cryotherapy offers an advantage over radiation therapy in that there is very little risk to surrounding tissue. In addition, cryotherapy avoids possible local and systemic side-effects of interferon and rituximab administration, respectively.

Cryotherapy for conjunctival lymphoma was first proposed in 1977 [34]. Subsequently, in a series of 37 lesions of biopsy-proven conjunctival lymphomas treated with excisional biopsy and liquid nitrogen cryotherapy, the authors reported local eradication in $65 \%(24 / 37)$, $92 \%(34 / 37)$, and $97 \%$ (36/37) of lesions after the first, second, and third cryotherapy treatment, respectively (average follow up time of 75 months) [41]. Most recently, a rare case of isolated T-cell conjunctival lymphoma in a 57-year-old female was treated with local 
excision and triple-freeze cryotherapy, resulting in local eradication without systemic involvement after 24 months of follow up [107].

\section{Cryotherapy for Intraocular Pathology}

\subsection{Retinal Tears and Detachments}

Retinal tears and detachments arise for physical separation of the neurosensory retina and the underlying retinal pigment epithelium (RPE). Retinal tears may arise from trauma or traction from the overlying vitreous. Retinal tears may then allow fluid influx between the neurosensory retina and the RPE, causing further extension of the separation and leading to a retinal detachment. Retinal detachments arising from retinal tears are referred to as rhegmatogenous retinal detachments. Retinal detachments arising from a tractional component without a tear are called tractional retinal detachments. Lastly, retinal detachments arising from a collection of exudate between the neurosensory retina and the RPE are called exudative retinal detachments.

The treatment of retinal tears and detachments are multiple and depend on the patient, the size and location of the lesion, as well as surgeon preference. Prophylactic treatment of retinal tears without detachment may include cryotherapy (Figure 5(a) and (b)) and/or laser therapy just outside of the tear to wall off the break. The goal of retinal detachment repair includes bringing the retina and RPE into contact to allow for reattachment and may include pneumatic retinopexy or pars plana vitrectomy with scleral buckle or silicone oil. In certain settings, further chorioretinal scarring, using cryotherapy or laser therapy, is used to adhere the detached retina to avoid repeat detachment.

The early history of cryotherapy use in retinal tear and detachment repair is described in detail in Section III. Briefly, cryotherapy of the eye was first reported by Bietti in 1933 to seal a retinal hole [17]. Shortly after, Deutschmann used cryosurgery to treat retinal detachments [18]. Bellows and Kelman created retinal cryopexy instruments for the treatment of retinal tears [22, 109]. Cryoretinopexy in conjunction with scleral buckling for retinal detachments was also described [24-26].

Yanoff reported results from a series of 100 eyes treated with transconjunctival cryotherapy to seal peripheral retinal breaks, with only 3 eyes developing retinal detachments and requiring additional procedures [110]. Wolfensberger and colleagues reported excellent results using prophylactic 360 degree peripheral retinal cryotherapy of fellow eyes after contralateral giant retinal tears [111]. Although generally safe, retinal cryopexy has been reported to cause cystoid macular edema [112], likely secondary to transient breakdown of the blood-retina barrier [113]. In addition, cases of retinal necrosis

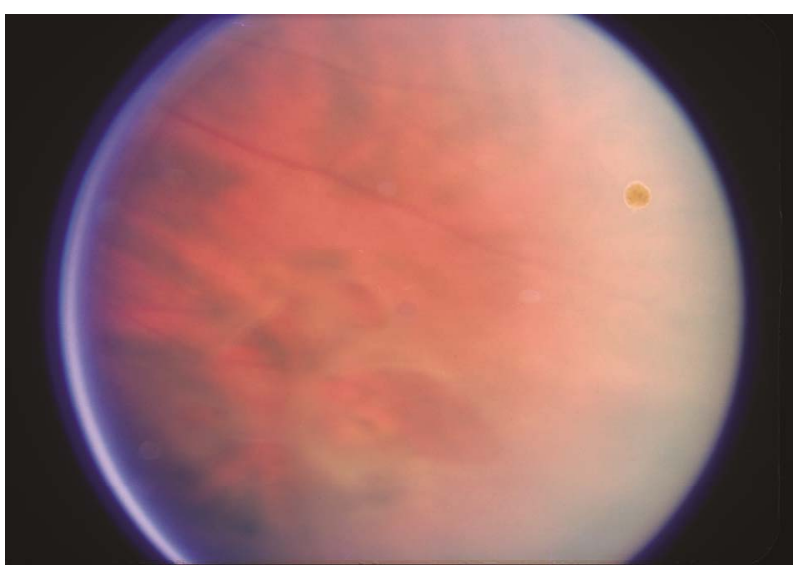

(a)

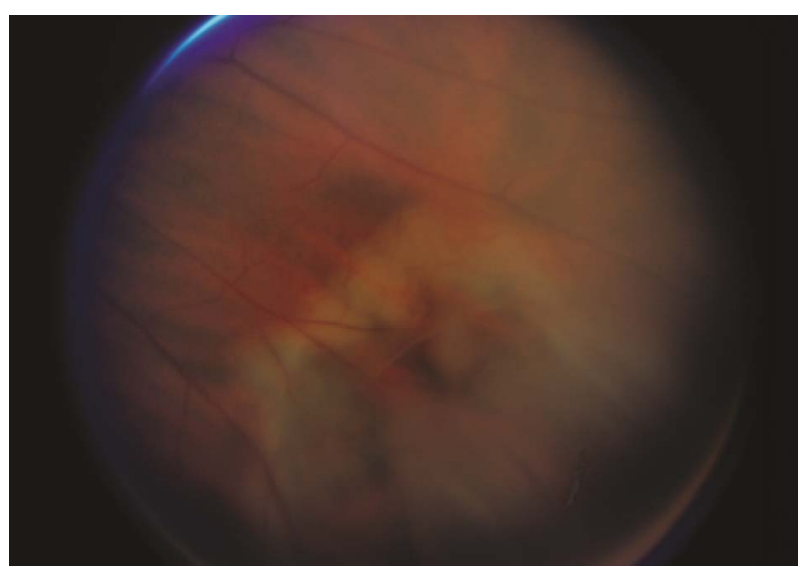

(b)

Figure 5. (a) Multiple retinal breaks; (b) Chorioretinal scarring after application of external cryotherapy to areas around retinal breaks in (a).

with overtreatment using cryotherapy have been reported [114].

The safety and efficacy profile of cryotherapy for retinal tear repair is comparable to other techniques. In a recent randomized clinical trial of patients undergoing repair of rhegmatogenous retinal detachments with either intraoperative cryotherapy or postoperative (1 month later) laser retinopexy, the authors found that reattachment and postoperative complication rates were similar in both groups [115]. Although the study found that visual recovery was faster in the retinopexy group, the difference in visual acuity after 6 months was not significant. In addition, cryotherapy intraoperatively during scleral buckling procedure provided the advantage of one intervention with lower costs.

\subsection{Retinopathy of Prematurity}

Retinopathy of prematurity (ROP, also called retrolental fibroplasia) is an ischemic retinopathy of premature and low birth weight infants. The incidence of ROP in the United States is about 1300 newborn children annually, 
with severe visual impairment in a large percentage. The risk of ROP is inversely proportional to birth weight, with $37 \%$ of infants weighing less than 750 grams developing severe ROP. The diagnosis of ROP is rarely made in infants with birth weights of greater than 2000 grams. The Preferred Practice Patterns of the American Academy of Ophthalmology recommends screening for newborns with less than 30 weeks of gestation and/or a birth weight of less than 1500 grams.

The development of retinal vasculature begins during week 16 of gestation and can progress to the final weeks of gestation. Premature birth, in conjunction with subsequent iatrogenic oxygen supplementation, halts and alters normal retinal vasculature development, leading to the onset of ROP and abnormal neovascularization. Severe ROP can progress to fibroglial proliferation, vitreoretinal traction, and retinal detachment.

Hindle and Leyton reported the first use of cryotherapy to prevent progression of ROP in 1978 [116]. This revolutionized the treatment of ROP, as prior treatments were limited. In this technique, trans-scleral cryotherapy is used to ablate areas of avascular retina and thereby prevent further neovascularization. In 1988, the first multicenter randomized trial of cryotherapy for treatment of ROP (the CRYO-ROP study) was reported [117]. Three month [117] and 12 month [118] data from this trial were promising, with cryotherapy reducing unfavorable outcomes by half. Five-year data from the CRYO-ROP study supported the safety and efficacy of cryotherapy treatment of ROP [119]. Ten-year data from the CRYO-ROP study showed that $44.4 \%$ of treated eyes (versus $62.1 \%$ of untreated eyes) were legally blind, showing long-term value from cryotherapy in preserving visual acuity in eyes with ROP [120]. More recently, laser therapy has become the standard of care for ROP management, while anti-vascular endothelial growth factor (anti-VEGF) therapy has shown promise as an additional modality for the treatment of ROP [121].

\subsection{Retinal Capillary Hemangiomas}

Retinal capillary hemangiomas (RCHs) are benign vascular tumors that may occur sporadically (sometimes referred to as von Hippel lesions) or in the setting of von Hippel-Lindau (VHL) disease. In the setting of VHL disease, RCHs are usually detected in the second or third decade of life, and seen in up to $60 \%$ of patients with VHL disease [122]. In a retrospective case series of 68 patients with $\mathrm{RCHs}$, it was found that $46 \%$ of patients had VHL disease [123]. The majority of patients with RCHs have no significant vision loss from the lesion [124], likely due to the predominately superotemporal and midperipheral retinal location of most RCHs [123].

Treatment of RCHs is based on size, location, associate edema, and effects of visual acuity. The majority of
RCHs may be safely observed [125]. Singh et al. reported that $82 \%$ (68 total patients) of observed $\mathrm{RCH}$ lesions remained stable with a mean follow up of 84 months [125]. For RCHs requiring treatment, laser photocoagulation and cryotherapy have been shown to be equally effective in controlling the growth of the lesion, as well as the associated retinal edema. In the same study by Singh and colleagues, $74 \%$ of treated RCHs remained controlled with one session of laser photocoagulation or cryotherapy [125].

\section{Summary and Conclusion}

Cryotherapy in ophthalmology has a rich history and continues to be an important supplement in the treatment of ophthalmic pathology. The use of cryotherapy in ophthalmology has helped advance maturing fields (such as cataract extraction), while in other instances revolutionized patient care (including retinopathy of prematurity and ocular surface malignancies). Further applications of cryotherapy in eye disease continue to emerge.

\section{Acknowledgements}

We'd like to thank Dr. Robert Watzke for his contribution of photos documenting the use of cryotherapy for retinal tear repair.

\section{REFERENCES}

[1] R. R. Lubritz, "Cryosurgery," Clinics in Dermatology, Vol. 5, No. 4, 1987, pp. 120-127. http://dx.doi.org/10.1016/0738-081X(87)90033-2

[2] S. M. Cooper and R. P. Dawber, "The History of Cryosurgery," Journal of the Royal Society of Medicine, Vol. 94, No. 4, 2001, pp. 196-201.

[3] A. Freiman and N. Bouganim, "History of Cryotherapy," Dermatology Online Journal, Vol. 11, No. 2, 2005, p. 9.

[4] A. Squazzi and D. Bracco, "A Historical Account of the Technical Means Used in Cryotherapy," Minerva Medica, Vol. 65, No. 70, 1974, pp. 3718-3722.

[5] A. Brock, "Greek Medicine, Being Extracts Illustrative of Medical Writers from Hippocrates to Galen," 2nd Edition, Dutton, New York, 1972.

[6] J. Arnott, "On the Treatment of Cancer by the Regulated Application of an Anaesthetic Temperature," Churchill, London, 1851

[7] A. White, "Liquid Air: Its Application in Medicine and Surgery," Medication Reconciliation, Vol. 56, 1899, pp. 109-112.

[8] A. White, "Possibilities of Liquid Air to the Physcian," JAMA, Vol. 36, No. 7, 1901, pp. 426-429.

http://dx.doi.org/10.1001/jama.1901.52470070012001d

[9] H. G. Irvine and D. D. Turnacliff, "Liquid Oxygen in Dermatology," Arch Dermatol Syphilol, Vol. 19, No. 2, 1929, pp. 270-280.

http://dx.doi.org/10.1001/archderm.1929.02380200098007 
[10] H. Allington, "Liquid Nitrogen in the Treatment of Skin Disease," California Medicine, Vol. 72, No. 3, 1950, p. 153.

[11] I. S. Cooper and T. Hirose, "Application of Cryogenic Surgery to Resection of Parenchymal Organs," The New England Journal of Medicine, Vol. 274, No. 1, 1966, pp. 15-18. http://dx.doi.org/10.1056/NEJM196601062740103

[12] S. Zacarian, "Cryogenics: The Cryolesion and the Pathogenesis of Cryonecrosis, in Cryosurgery for Skin Cancer and Cutaneous Disorders," St. Louis, Mosby, 1985, pp. $1-30$.

[13] P. Lepivert, "Predictability of Cryonecrosis by Tissue Impedancemetry," Low Temperature Medicine, Vol. 4, 1977, p. 129.

[14] S. A. Zacarian, "Cryosurgery of Cutaneous Carcinomas. An 18-Year Study of 3,022 Patients with 4,228 Carcinomas," Journal of the American Academy of Dermatology, Vol. 9, No. 6, 1983, pp. 947-956. http://dx.doi.org/10.1016/S0190-9622(83)70213-6

[15] D. Bracco, "The Historic Development of Cryosurgery," Clinics in Dermatology, Vol. 8, No. 1, 1990, pp. 1-4. http://dx.doi.org/10.1016/0738-081X(90)90061-5

[16] G. F. Graham, "Cryosurgery," Clinics in Plastic Surgery, Vol. 20, No. 1, 1993, pp. 131-147.

[17] G. Bietti, "Ricerche Sulle Variazione di Temperature di Alcune Zone del Bulbo Oculaire per Diatermocoagulaxioni Episclerali, Termocauterizazioni e Criocausticazioni," Bollettino d'Oculistica, Vol. 12, 1933, pp. 14271457.

[18] R. Deutschmann, "Die Behandlung der Netzhautablosung mit Jodtinkur und Kohlensaureschnee," Klin Montasbl Augenh, Vol. 94, 1935, p. 349.

[19] T. Krwawicz, "Intracapsular Extraction of Intumescent Cataract by Application of Low Temperature," The British Journal of Ophthalmology, Vol. 45, No. 4, 1961, pp. 279-283. http://dx.doi.org/10.1136/bjo.45.4.279

[20] S. P. Amoils, "The Joule Thomson Cryoprobe," Archives of Ophthalmology, Vol. 78, No. 2, 1967, pp. 201-207. http://dx.doi.org/10.1001/archopht.1967.00980030203014

[21] J. G. Bellows, "Indications and Technique of Cryoextraction of Cataracts," Archives of Ophthalmology, Vol. 73, No. 4, 1965, pp. 476-481. http://dx.doi.org/10.1001/archopht.1965.00970030478006

[22] J. G. Bellows, "The Application of Cryogenic Techniques in Ophthalmology," American Journal of Ophthalmology, Vol. 57, 1964, pp. 29-33.

[23] C. D. Kelman, "Cryosurgery for Cataract Extracction and the Treatment of Other Eye Diseases," Highlights Ophthalmol, Vol. 7, 1964, pp. 181-209.

[24] J. G. Bellows, "Cryotherapy of Ocular Disease," J.B. Lippincott Co., Philadelphia, 1966.

[25] H. A. Lincoff, J. M. McLean and H. Nano, "Cryosurgical Treatment of Retinal Detachment. Transactions," American Academy of Ophthalmology and Otolaryngology, Vol. 68, 1964, pp. 412-432.

[26] C. L. Schepens, I. D. Okamura and R. J. Brockhurst, "The Scleral Buckling Procedures. I. Surgical Techniques and
Management," Archives of Ophthalmology, Vol. 58, No. 6, 1957, pp. 797-811.

http://dx.doi.org/10.1001/archopht.1957.00940010819003

[27] J. I. Barraquer, "Method for Cutting Lamellar Grafts in Frozen Cornea, New Orientation for Refractive Surgery," Arch Soc Am Ophthal Optom, Vol. 1, 1958, pp. 271-286.

[28] Herbert E. Kaufman, "Preserving Corneas by Freezing," Archives of Ophthalmology, Vol. 73, No. 6, 1965, pp. 907-908.

http://dx.doi.org/10.1001/archopht.1965.00970030909029

[29] S. A. Zacarian, "Cancer of the Eyelid-A Cryosurgical Approach," Annals of Ophthalmology, Vol. 4, No. 6, 1972, pp. 473-480.

[30] H. E. Farris and F. T. Fraunfelder, "Cryosurgical Treatment of Ocular Squamous Cell Carcinoma of Cattle," Journal of the American Veterinary Medical Association, Vol. 168, No. 3, 1976, pp. 213-216.

[31] H. E. Farris, F. T. Fraunfelder and C. H. Frith, "A Simple Cryosurgical Unit for Treatment of Animal Tumors," Veterinary Medicine, Small Animal Clinician, Vol. 70, No. 3, 1975, pp. 299-302.

[32] F. T. Fraunfelder, H. Howard and M. L. Ray, "New Therapy Method for Cancer Eye in Cattle," Southern Beef Producer, Vol. 5, 1974.

[33] F. T. Fraunfelder, et al., "The Role of Cryosurgery in External Ocular and Periocular Disease," Transactions. Section on Ophthalmology. American Academy of Ophthalmology and Otolaryngology, Vol. 83, No. 4, 1977, pp. 713-724.

[34] F. T. Fraunfelder, H. E. Farris Jr. and T. R. Wallace, "Cryosurgery for Ocular and Periocular Lesions," The Journal of Dermatologic Surgery and Oncology, Vol. 3, No. 4, 1977, pp. 422-427.

[35] F. T. Fraunfelder, et al., "Results of Cryotherapy for Eyelid Malignancies," American Journal of Ophthalmology, Vol. 97, No. 2, 1984, pp. 184-188.

[36] E. G. Kuflik and A. A. Gage, "The Five-Year Cure Rate Achieved by Cryosurgery for Skin Cancer," Journal of the American Academy of Dermatology, Vol. 24, No. 6, 1991, pp. 1002-1004. http://dx.doi.org/10.1016/0190-9622(91)70160-4

[37] P. J. Holt, "Cryotherapy for Skin Cancer: Results over a 5-Year Period Using Liquid Nitrogen Spray Cryosurgery," The British Journal of Dermatology, Vol. 119, No. 2, 1988, pp. 231-240. http://dx.doi.org/10.1111/j.1365-2133.1988.tb03205.x

[38] E. G. Kuflik and A. A. Gage, "Recurrent Basal Cell Carcinoma Treated with Cryosurgery," Journal of the American Academy of Dermatology, Vol. 37, No. 1, 1997, pp. 82-84. http://dx.doi.org/10.1016/S0190-9622(97)70215-9

[39] F. Jaramillo-Ayerbe, "Cryosurgery in Difficult to Treat Basal Cell Carcinoma," International Journal of Dermatology, Vol. 39, No. 3, 2000, pp. 223-229. http://dx.doi.org/10.1046/j.1365-4362.2000.00952.x

[40] F. T. Fraunfelder, et al., "Cryosurgery for Malignancies of the Eyelid," Ophthalmology, Vol. 87, No. 6, 1980, pp. 461-465.

[41] M. D. Eichler and F. T. Fraunfelder, "Cryotherapy for 
Conjunctival Lymphoid Tumors," American Journal of Ophthalmology, Vol. 118, No. 4, 1994, pp. 463-467.

[42] F. A. Jakobiec, et al., "Cryotherapy for Conjunctival Primary Acquired Melanosis and Malignant Melanoma. Experience with 62 Cases," Ophthalmology, Vol. 95, No. 8, 1988, pp. 1058-1070.

[43] F. T. Fraunfelder and D. Wingfield, "Management of Intraepithelial Conjunctival Tumors and Squamous Cell Carcinomas," American Journal of Ophthalmology, Vol. 95, No. 3, 1983, pp. 359-363.

[44] F. W. Fraunfelder and F. T. Fraunfelder, "Liquid Nitrogen Cryotherapy of a Conjunctival Vascular Tumor," Cornea, Vol. 24, No. 1, 2005, pp. 116-117. http://dx.doi.org/10.1097/01.ico.0000134185.55310.1d

[45] C. D. Kelman and I. S. Cooper, "Cryogenic Ophthalmic Surgery," American Journal of Ophthalmology, Vol. 56, 1963, pp. 731-739.

[46] T. D. Wilkes and F. T. Fraunfelder, "Principles of Cryosurgery," Ophthalmic Surgery, Vol. 10, No. 8, 1979, pp. 21-30.

[47] D. L. Wingfield and F. T. Fraunfelder, "Possible Complications Secondary to Cryotherapy," Ophthalmic Surgery, Vol. 10, No. 8, 1979, pp. 47-55.

[48] S. M. Tucker, et al., "Scleral Melt after Cryotherapy for Conjunctival Melanoma," Ophthalmology, Vol. 100, No. 4, 1993, pp. 574-577.

[49] J. H. Sullivan, "Cryosurgery in Ophthalmic Practice," Ophthalmic Surgery, Vol. 10, No. 8, 1979, pp. 37-41.

[50] W.-L. Yang, T. Addona, D. G. Nair, L. X. Qi and T. S. Ravikumar, "Apoptosis Induced by Cryoinjury in Human Colorectal Cancer Cells Is Associated with Mitochondrial Dysfunction," International Journal of Cancer, Vol. 103, No. 3, 2003, pp. 360-369. http://dx.doi.org/10.1002/ijc.10822

[51] H. T. Mergman, "Mechanics of Freezing in Living Cells and Tissues," Science, Vol. 124, 1956, pp. 15-30.

[52] D. Torre, "Cryosurgical Instrumentation and Depth Dose Monitoring," In: E. D.-S. Breitbart, Ed., Clinics in Dermatology: Advances in Cryosurgery, Elsevier, New York, 1990, p. 48.

[53] G. D’Aversa, et al., "Advancing Wave-Like Epitheliopathy. Clinical Features and Treatment," Ophthalmology, Vol. 104, No. 6, 1997, pp. 962-969. http://dx.doi.org/10.1016/S0161-6420(97)30199-7

[54] F. W. Fraunfelder, "Liquid Nitrogen Cryotherapy of Advancing Wavelike Epitheliopathy," Cornea, Vol. 25, No. 2, 2006, pp. 196-198. http://dx.doi.org/10.1097/01.ico.0000170691.67584.ec

[55] I. Leibovitch, et al., "Periocular and Orbital Amyloidosis: Clinical Characteristics, Management, and Outcome," Ophthalmology, Vol. 113, No. 9, 2006, pp. 1657-1664. http://dx.doi.org/10.1016/j.ophtha.2006.03.052

[56] H. Demirci, et al., "Conjunctival Amyloidosis: Report of Six Cases and Review of the Literature," Survey of Ophthalmology, Vol. 51, No. 4, 2006, pp. 419-433. http://dx.doi.org/10.1016/j.survophthal.2006.04.007

[57] M. B. Pepys, "Amyloidosis," Annual Review of Medicine,
Vol. 57, 2006, pp. 223-241.

http://dx.doi.org/10.1146/annurev.med.57.121304.131243

[58] F. W. Fraunfelder, "Liquid Nitrogen Cryotherapy for Surface Eye Disease (an AOS Thesis)," Transactions of the American Ophthalmological Society, Vol. 106, 2008, pp. 301-324.

[59] F. W. Fraunfelder, "Liquid Nitrogen Cryotherapy for Conjunctival Amyloidosis," Archives of Ophthalmology, Vol. 127, No. 5, 2009, pp. 645-648. http://dx.doi.org/10.1001/archophthalmol.2008.535

[60] H. D. Perry and A. J. Cossari, "Chronic Lymphangiectasis in Turner's Syndrome," The British Journal of Ophthalmology, Vol. 70, No. 5, 1986, pp. 396-399. http://dx.doi.org/10.1136/bjo.70.5.396

[61] L. M. Jampol and K. C. Nagpal, "Hemorrhagic Lymphangiectasia of the Conjunctiva," American Journal of Ophthalmology, Vol. 85, 1978, pp. 419-420.

[62] I. A. Wasfy, "Lymphangiectasia Haemorrhagica Conjunctivae: Report of Three Cases with a Note on Successful Treatment with Cryosurgery in One Case," Bulletin of the Ophthalmological Society of Egypt, Vol. 68, 1975, pp. 37-44.

[63] F. W. Fraunfelder, "Liquid Nitrogen Cryotherapy of Conjunctival Lymphangiectasia: A Case Series," Archives of Ophthalmology, Vol. 127, No. 12, 2009, pp. 1686-1687. http://dx.doi.org/10.1001/archophthalmol.2009.306

[64] A. Rothova, "Ocular Involvement in Sarcoidosis," The British Journal of Ophthalmology, Vol. 84, No. 1, 2000, pp. 110-116. http://dx.doi.org/10.1136/bjo.84.1.110

[65] J. Y. Oh and W. R. Wee, "Cyclosporine for Conjunctival Sarcoidosis," Ophthalmology, Vol. 115, No. 1, 2008, p. 222. http://dx.doi.org/10.1016/j.ophtha.2007.08.024

[66] F. W. Fraunfelder and D. S. Dhoot, "Successful Treatment of Conjunctival Sarcoidosis with Local Cryotherapy," Ophthalmic Surgery, Lasers \& Imaging: The Official Journal of the International Society for Imaging in the Eye, 2010, pp. 1-4.

[67] I. J. Wang, et al., "Mechanism of Abnormal Elastin Gene Expression in the Pinguecular Part of Pterygia," The American Journal of Pathology, Vol. 157, No. 4, 2000, pp. 1269-1276. http://dx.doi.org/10.1016/S0002-9440(10)64642-1

[68] M. T. Coroneo, N. Di Girolamo and D. Wakefield, "The Pathogenesis of Pterygia," Current Opinion in Ophthalmology, Vol. 10, No. 4, 1999, pp. 282-288. http://dx.doi.org/10.1097/00055735-199908000-00011

[69] T. M. Nolan, et al., "The Role of Ultraviolet Irradiation and Heparin-Binding Epidermal Growth Factor-Like Growth Factor in the Pathogenesis of Pterygium," The American Journal of Pathology, Vol. 162, No. 2, 2003, pp. 567-574.

http://dx.doi.org/10.1016/S0002-9440(10)63850-3

[70] M. Gebhardt, et al., "Differential Expression of Vascular Endothelial Growth Factor Implies the Limbal Origin of Pterygia," Ophthalmology, Vol. 112, No. 6, 2005, pp. 1023-1030.

http://dx.doi.org/10.1016/j.ophtha.2005.01.023

[71] P. Sakoonwatanyoo, D. T. Tan and D. R. Smith, "Expres- 
sion of p63 in Pterygium and Normal Conjunctiva," Cornea, Vol. 23, No. 1, 2004, pp. 67-70. http://dx.doi.org/10.1097/00003226-200401000-00011

[72] Donaldson, K.E.A., E.C., "Recent Advances in Pterygium Excision," Cont Ophthalmol, Vol. 2, 2003, pp. 1-7.

[73] F. W. Fraunfelder, "Cryotherapy for Pterygia," Ophthalmology, Vol. 115, No. 12, 2008, pp. 2314-2314.

[74] I. Cher, "Superior Limbic Keratoconjunctivitis: Multifactorial Mechanical Pathogenesis," Clinical \& Experimental Ophthalmology, Vol. 28, No. 3, 2000, pp. 181-184. http://dx.doi.org/10.1046/j.1442-9071.2000.00284.x

[75] N. Yokoi, et al., "New Surgical Treatment for Superior Limbic Keratoconjunctivitis and Its Association with Conjunctivochalasis," American Journal of Ophthalmology, Vol. 135, No. 3, 2003, pp. 303-308. http://dx.doi.org/10.1016/S0002-9394(02)01975-X

[76] J. D. Nelson, "Superior Limbic Keratoconjunctivitis (SLK)," Eye, Vol. 3, Pt. 2, 1989, pp. 180-189. http://dx.doi.org/10.1038/eye.1989.26

[77] H. Y. Yang, et al., "Lacrimal Punctal Occlusion for the Treatment of Superior Limbic Keratoconjunctivitis," American Journal of Ophthalmology, Vol. 124, No. 1, 1997 , pp. 80-87.

[78] E. Goto, et al., "Treatment of Superior Limbic Keratoconjunctivitis by Application of Autologous Serum," Cornea, Vol. 20, No. 8, 2001, pp. 807-810. http://dx.doi.org/10.1097/00003226-200111000-00006

[79] H. D. Perry, et al., "Topical Cyclosporine A $0.5 \%$ as a Possible New Treatment for Superior Limbic Keratoconjunctivitis," Ophthalmology, Vol. 110, No. 8, 2003, pp. 1578-1581.

http://dx.doi.org/10.1016/S0161-6420(03)00538-4

[80] I. J. Udell, A. C. Guidera and J. Madani-Becker, "Ketotifen Fumarate Treatment of Superior Limbic Keratoconjunctivitis," Cornea, Vol. 21, No. 8, 2002, pp. 778780 .

http://dx.doi.org/10.1097/00003226-200211000-00009

[81] S. Watson, A. B. Tullo and F. Carley, "Treatment of Superior Limbic Keratoconjunctivitis with a Unilateral Bandage Contact Lens," The British Journal of Ophthalmology, Vol. 86, No. 4, 2002, pp. 485-486. http://dx.doi.org/10.1136/bjo.86.4.485

[82] R. D. Grutzmacher, R. S. Foster and L. S. Feiler, "Lodoxamide Tromethamine Treatment for Superior Limbic Keratoconjunctivitis," American Journal of Ophthalmology, Vol. 120, No. 3, 1995, pp. 400-402.

[83] I. A. Mackie, "Management of Superior Limbic Keratoconjunctivitis with Botulinum Toxin," Eye, Vol. 9, Pt. 1, 1995, pp. 143-144. http://dx.doi.org/10.1038/eye.1995.25

[84] Y. Ohashi, et al., "Vitamin A Eyedrops for Superior Limbic Keratoconjunctivitis," American Journal of Ophthalmology, Vol. 105, No. 5, 1988, pp. 523-527.

[85] E. F. Kadrmas and G. B. Bartley, "Superior Limbic Keratoconjunctivitis. A Prognostic Sign for Severe Graves Ophthalmopathy," Ophthalmology, Vol. 102, No. 10, 1995, pp. 1472-1475.

[86] F. W. Fraunfelder, "Liquid Nitrogen Cryotherapy of Superior Limbic Keratoconjunctivitis," American Journal of
Ophthalmology, Vol. 147, No. 2, 2009, pp. 234-238.

[87] J. H. Sullivan, "The Use of Cryotherapy for Trichiasis. Transactions. Section on Ophthalmology," American Academy of Ophthalmology and Otolaryngology, Vol. 83, No. 4, Pt. 1, 1977, pp. 708-712.

[88] F. T. Fraunfelder and G. J. Petursson, "The Use of Liquid Nitrogen Cryospray for Treatment of Trichiasis," Ophthalmic Surgery, Vol. 10, No. 8, 1979, pp. 42-46.

[89] C. D. Rice, R. C. Kersten and S. Al-Hazzaa, "Cryotherapy for Trichiasis in Trachoma," Archives of Ophthalmology, Vol. 107, No. 8, 1989, pp. 1180-1182. http://dx.doi.org/10.1001/archopht.1989.01070020246033

[90] M. J. Elder and W. Bernauer, "Cryotherapy for Trichiasis in Ocular Cicatricial Pemphigoid," The British Journal of Ophthalmology, Vol. 78, No. 10, 1994, pp. 769-771. http://dx.doi.org/10.1136/bjo.78.10.769

[91] N. Kumagai, et al., "Role of Structural Cells of the Cornea and Conjunctiva in the Pathogenesis of Vernal Keratoconjunctivitis," Progress in Retinal and Eye Research, Vol. 25, No. 2, 2006, pp. 165-187.

http://dx.doi.org/10.1016/j.preteyeres.2005.09.002

[92] G. Singh, "Cryosurgery in Palpebral Vernal Catarrh," Annals of Ophthalmology, Vol. 14, No. 3, 1982, pp. 252254.

[93] A. Abiose and M. Merz, "Cryosurgery in the Management of Vernal Keratoconjunctivitis," Annals of Ophthalmology, Vol. 15, No. 8, 1983, pp. 744-747.

[94] A. T. Mtanda and J. L. Sangawe, "Cryosurgery in Vernal Catarrh," Tropical and Geographical Medicine, Vol. 35, No. 4, 1983, pp. 381-383.

[95] T. Sankarkumar, A. Panda and S. K. Angra, "Efficacy of Cryotherapy in Vernal Catarrh," Annals of Ophthalmology, Vol. 24, No. 7, 1992, pp. 253-256.

[96] D. Jiang, M. Zhang and Y. Hu, "Resection and Cryotherapy Combined with Amniotic Membrane Transplantation for the Treatment of Vernal Keratoconjunctivitis with Giant Papillae," Journal of Huazhong University of Science and Technology. Medical Sciences, Vol. 26, No. 5 , 2006, pp. 618-620.

[97] P. Gloor and G. Alexandrakis, "Clinical Characterization of Primary Acquired Melanosis," Investigative Ophthalmology \& Visual Science, Vol. 36, No. 8, 1995, pp. 1721-1729.

[98] J. A. Shields, et al., "Primary Acquired Melanosis of the Conjunctiva: Experience with 311 Eyes," Transactions of the American Ophthalmological Society, Vol. 105, 2007, pp. 61-71, Discussion 71-72.

[99] S. Brownstein, et al., "Cryotherapy for Precancerous Melanosis (Atypical Melanocytic Hyperplasia) of the Conjunctiva," Archives of Ophthalmology, Vol. 99, No. 7, 1981, pp. 1224-1231.

http://dx.doi.org/10.1001/archopht.1981.03930020098009

[100] J. A. Shields, C. L. Shields and P. De Potter, "Surgical Management of Conjunctival Tumors. The 1994 Lynn B. McMahan Lecture," Archives of Ophthalmology, Vol. 115, No. 6, 1997, pp. 808-815.

http://dx.doi.org/10.1001/archopht.1997.01100150810025

[101] R. Folberg, I. W. McLean and L. E. Zimmerman, "Con- 
junctival Melanosis and Melanoma," Ophthalmology, Vol. 91, No. 6, 1984, pp. 673-678.

[102] A. S. Grove Jr., "Melanomas of the Conjunctiva," International Ophthalmology Clinics, Vol. 20, No. 2, 1980, pp. 161-175.

[103] F. A. Jakobiec, et al., "Combined Surgery and Cryotherapy for Diffuse Malignant Melanoma of the Conjunctiva," Archives of Ophthalmology, Vol. 98, No. 8, 1980, pp. 1390-1396.

http://dx.doi.org/10.1001/archopht.1980.01020040242005

[104] J. M. McDonnell, A. J. Mayr and W. J. Martin, "DNA of Human Papillomavirus Type 16 in Dysplastic and Malignant Lesions of the Conjunctiva and Cornea," The New England Journal of Medicine, Vol. 320, No. 22, 1989, pp. 1442-1446.

http://dx.doi.org/10.1056/NEJM198906013202202

[105] G. Peksayar, M. K. Soyturk and M. Demiryont, "LongTerm Results of Cryotherapy on Malignant Epithelial Tumors of the Conjunctiva," American Journal of Ophthalmology, Vol. 107, No. 4, 1989, pp. 337-340.

[106] M. Tunc, et al., "Intraepithelial and Invasive Squamous Cell Carcinoma of the Conjunctiva: Analysis of 60 Cases," The British Journal of Ophthalmology, Vol. 83, No. 1, 1999, pp. 98-103. http://dx.doi.org/10.1136/bjo.83.1.98

[107] A. Al-Muammar, W. G. Hodge and J. Farmer, "Conjunctival T-Cell Lymphoma: A Clinicopathologic Case Report," Ophthalmology, Vol. 113, No. 3, 2006, pp. 459461. http://dx.doi.org/10.1016/j.ophtha.2005.10.042

[108] P. S. Tsai and K. A. Colby, "Treatment of Conjunctival Lymphomas," Seminars in Ophthalmology, Vol. 20, No. 4, 2005, pp. 239-246. http://dx.doi.org/10.1080/08820530500350845

[109] C. D. Kelman, "Cryosurgery for Cataract Extraction and the Treatment of Other Eye Diseases," Highlights of Ophthalmology, Vol. 7, 1964, pp. 181-209.

[110] M. Yanoff, "Prophylactic Cryotherapy of Retinal Breaks," Annals of Ophthalmology, Vol. 9, No. 3, 1977, pp. 283286.

[111] T. J. Wolfensberger, G. W. Aylward and P. K. Leaver, "Prophylactic 360 Degrees Cryotherapy in Fellow Eyes of Patients with Spontaneous Giant Retinal Tears," Ophthalmology, Vol. 110, No. 6, 2003, pp. 1175-1177. http://dx.doi.org/10.1016/S0161-6420(03)00256-2

[112] R. W. Kimball, P. H. Morse and W. E. Benson, "Cystoid Macular Edema after Cryotherapy," American Journal of Ophthalmology, Vol. 86, No. 4, 1978, pp. 572-573.

[113] E. H. Jaccoma, B. P. Conway and P. A. Campochiaro, "Cryotherapy Causes Extensive Breakdown of the BloodRetinal Barrier. A Comparison with Argon Laser Photocoagulation," Archives of Ophthalmology, Vol. 103, No. 11, 1985, pp. 1728-1730. http://dx.doi.org/10.1001/archopht.1985.01050110124039

[114] R. J. Bowman, et al., "Retinal Necrosis as a Complication of Cryotherapy," Eye, Vol. 8, Pt. 5, 1994, pp. 600-601. http://dx.doi.org/10.1038/eye.1994.146

[115] R. P. Lira, et al., "Cryotherapy vs Laser Photocoagulation in Scleral Buckle Surgery: A Randomized Clinical Trial," Archives of Ophthalmology, Vol. 128, No. 12, 2010, pp. 1519-1522.

http://dx.doi.org/10.1001/archophthalmol.2010.271

[116] N. W. Hindle and J. Leyton, "Prevention of Cicatricial Retrolental Fibroplasia by Cryotherapy," Canadian Journal of Ophthalmology, Vol. 3, No. 4, 1978, pp. 277-282.

[117] Cryotherapy for Retinopathy of Prematurity Cooperative Group, "Multicenter Trial of Cryotherapy for Retinopathy of Prematurity. Preliminary Results," Archives of Ophthalmology, Vol. 106, No. 4, 1988, pp. 471-479.

http://dx.doi.org/10.1001/archopht.1988.01060130517027

[118] Cryotherapy for Retinopathy of Prematurity Cooperative Group, "The Natural Ocular Outcome of Premature Birth and Retinopathy. Status at 1 Year," Archives of Ophthalmology, Vol. 112, No. 7, 1994, pp. 903-912.

http://dx.doi.org/10.1001/archopht.1994.01090190051021

[119] Cryotherapy for Retinopathy of Prematurity Cooperative Group, "Multicenter Trial of Cryotherapy for Retinopathy of Prematurity. Snellen Visual Acuity and Structural Outcome at 5 1/2 Years after Randomization," Archives of Ophthalmology, Vol. 114, No. 4, 1996, pp. 417-424. http://dx.doi.org/10.1001/archopht.1996.01100130413008

[120] Cryotherapy for Retinopathy of Prematurity Cooperative Group, "Multicenter Trial of Cryotherapy for Retinopathy of Prematurity: Ophthalmological Outcomes at 10 Years," Archives of Ophthalmology, Vol. 119, No. 8, 2001, pp. 1110-1118.

http://dx.doi.org/10.1001/archopht.119.8.1110

[121] H. A. Mintz-Hittner, K. A. Kennedy and A. Z. Chuang, "Efficacy of Intravitreal Bevacizumab for Stage 3+ Retinopathy of Prematurity," The New England Journal of Medicine, Vol. 364, No. 7, 2011, pp. 603-615. http://dx.doi.org/10.1056/NEJMoa1007374

[122] R. R. Lonser, et al., "Von Hippel-Lindau Disease," Lancet, Vol. 361, No. 9374, 2003, pp. 2059-2067. http://dx.doi.org/10.1016/S0140-6736(03)13643-4

[123] A. D. Singh, et al., "Retinal Capillary Hemangioma: A Comparison of Sporadic Cases and Cases Associated with von Hippel-Lindau Disease," Ophthalmology, Vol. 108, No. 10, 2001, pp. 1907-1911. http://dx.doi.org/10.1016/S0161-6420(01)00758-8

[124] E. Y. Chew, "Ocular Manifestations of von Hippel-Lindau Disease: Clinical and Genetic Investigations," Transactions of the American Ophthalmological Society, Vol. 103, 2005, pp. 495-511.

[125] A. D. Singh, et al., "Treatment of Retinal Capillary Hemangioma," Ophthalmology, Vol. 109, No. 10, 2002, pp. 1799-1806. http://dx.doi.org/10.1016/S0161-6420(02)01177-6 